\title{
UN RETO DE LAS \\ UNIVERSIDADES PÚBLICAS: DE LA INFORMACIÓN A LA COMUNICACIÓN ${ }^{1}$
}

\section{Carlos Sandoval García}

"Globalización" es quizá la palabra más citada por políticos e intelectuales en los últimos años. En este panorama, es difícil evitar lugares comunes. Por eso, esta invitación es particularmente difícil. Intentaré elaborar unas pocas ideas sobre algunas de las múltiples relaciones entre globalización, universidades públicas y comunicación. Quisiera organizar mi participación en torno a tres temas.

En primer lugar, intentaré mostrar que los orígenes de los procesos globalizadores y de las universidades son

1. Este documento fue presentado en el Primer taller de identificación de necesidades del sector comunicación universitaria, organizado por el Centro Nacional de Tecnología el 30 de marzo 2001. 
semejantes, pues ambos están emparentados con el inicio de la modernidad.

En segundo lugar, intentaré reflexionar sobre algunas de las explicaciones que las ciencias sociales brindan acerca de la globalización, poniendo énfasis en la relación entre procesos globalizantes, modos de comunicación y representación de la alteridad.

En tercer lugar, quisiera explorar algunos desafíos que los procesos globalizadores o globalizantes le imponen a las estrategias de comunicación de las universidades públicas. Quisiera referirme tanto a las demandas de comunicación externa como a las de comunicación interna, enfatizando la necesidad de incorporar tres criterios a mi modo de ver indispensables: capacidad prospectiva, capacidad propositiva $\mathrm{y}$ actitud proactiva.

\section{Algunos hilos históricos}

La globalización se asocia con internet y el fracaso de los regímenes de socialismo de estado sobre todo en Europa. ¿Pero qué hay de original en lo que hoy llamamos globalización?. Una de las dificultades para contestar esta pregunta surge de la separación entre ciencias sociales e historia, la cual impide ver líneas de continuidad en la larga duración, es decir, en períodos prolongados. Pese a este impedimento, intentemos situarnos en el inicio de la modernidad, en donde la globalización, los medios de comunicación y las universidades experimentan su consolidación. Esta perspectiva histórica quizá nos brinde más criterios para interpretar el presente y sobre todo, para vislumbrar escenarios futuros. 
Desde el siglo XV y sobre todo a partir del siglo XVIII, la organización política predominante empieza a ser la nación/estado. La enorme mayoría de los estados existentes en la actualidad no cuentan con más de dos siglos de existencia como Ernest Gellner ha notado. En este mismo período, las potencias europeas se expanden a lo largo del mundo. España, Portugal y luego Francia e Inglaterra dominan territorios en diferentes continentes. Es interesante cómo desde sus orígenes la nación/estado y los procesos globalizantes han coexistido y se han afectado mutuamente. De hecho el sentido de superioridad europeo, sobre todo presente en.Francia, Inglaterra o Alemania, no hubiese surgido sin la expansión colonial. Vale la pena recordar que si nosotros en estos momentos pudiéramos tener un mapa mundial en mente, podríamos notar cómo la modernidad se ha construido en torno al Atlántico. La humanidad en los últimos siglos ha estado viajando una y otra vez en torno a ambos lados del Atlántico. Eric Hobsbawn nos advierte incluso que en términos relativos hubo más inmigración en el siglo XIX que en el XX. Estos viajes han sido interpretados como producto de la ilustración, pero también pueden ser leídos como testimonios de la esclavitud y el racismo. De hecho es en estos viajes que el color de la piel, sobre todo el color negro, se convirtió en un modo de diferenciar a las personas, como Stuart Hall y Paul Gilroy, entre otros, ha mostrado de manera convincente.

Estos desarrollos institucionales de las naciones y la expansión colonial coincidieron con dos procesos que nos interesan en esta mañana. Uno es el desarrollo de los medios y el otro lo constituyen los procesos de secularización, íntimamente relacionados con el crecimiento de las universidades. De hecho, Benedict Anderson apunta que sin el desarrollo de la prensa, la emergencia de las naciones al 
menos en Europa Central, no hubiese tenido lugar. Otros autores, como Carlos Monsivaís, han sugerido que en América Latina, el papel que desempeñó la prensa en Europa, ha sido ocupado por la radio y el cine.

Por otra parte, en este mismo período, el desarrollo tecnológico, la imprenta por ejemplo y sobre todo las universidades, generaron procesos de secularización, los cuales indican, para seguir la expresión clásica de Max Weber, un desencantamiento del mundo. La vida no es más producto de designios divinos. El ser humano, al menos el europeo porque los nativos no eran considerados individuos incluso por muchos de los partidarios de la Ilustración, estaba llamado, en virtud de estos procesos de secularización, a ser consciente de sus propias decisiones. De ahí que algunos autores, consideran que si algo caracteriza la Modernidad es la capacidad reflexiva de las personas, capacidad que se ha asociado a las universidades, instituciones que constituirían el espacio en donde es posible explorar el tiempo que se vive. En otras palabras, las universidades serían una institución clave de la modernidad.

De lo dicho hasta acá, podríamos sintetizar que los procesos globalizantes, estado/nación, los medios y las universidades tienen más en común de lo que a menudo estamos dispuestos a aceptar. Estos fenómenos surgen en el contexto de la modernidad, la cual podría caracterizarse, como ya se ha dicho, por la secularización, pero también por la emergencia del capitalismo y la producción industrial.

Es importante acotar también que la modernidad engendró también a sus "otros", en relación con los cuales las ideas de progreso y civilización tomaron forma. Peter Wagner nota que en el eje temporal, los "otros" son sinónimos 
de "retraso", es decir, lo opuesto a la modernidad misma. La segunda dimensión es espacial, la cual es descrita a través de la distinción entre quienes son portadores de "progreso" y los excluidos, considerados "bárbaros". Una tercera forma de exclusión toma lugar dentro de las sociedades modernas mismas y luego trasladadas a las sociedades "atrasadas" a través de exclusiones de clase, género y discapacidad. Así, las clases trabajadoras (entendidas como los hombres), las mujeres y las personas no heterosexuales o discapacitadas son estigmatizadas en diversas formas y por diferentes medios. La distinción -Wagner sostiene- entre razón y sin razón está en la base de los intentos modernos de establecer límites simbólicos. Queda por interrogarse qué papel pueden cumplir en estos tiempos llamados por unos de modernidad tardía o postmodernidad, sobre todo en América Latina, en donde parece que vivimos, como ha sugerido Norbert Lechner, una postmodernidad sin modernidad.

\section{Interrogando la globalización}

Si aceptamos que las universidades son las instituciones modernas llamadas a impulsar la actividad reflexiva, no podríamos dudar de la importancia de interrogar los procesos globalizadores. Ya hemos dicho que la globalización es todo menos un fenómeno reciente. Bien se podría decir que si algo define la globalización es el carácter expansivo del capitalismo, tanto en la necesidad de disminuir costos de producción como de explorar nuevos mercados, con el propósito de evitar crisis. Quizá lo nuevo de los últimos años sea las ideologías neoliberales que sustentan la globalización y la promesa del "e-commerce" como la clave del éxito de los "nuevos empresarios, quienes desde una pequeña habitación ingresan a la economía "punto.com". 
Néstor García Canclini sugiere distinguir entre internacionalización, transnacionalización y globalización. La internacionalización es asociada con la expansión colonial, la cual se consolida en el siglo XIX. La transnacionalización se revela en la expansión de la producción, la cual deja de estar organizada en un determinado país y procura encontrar mano de obra calificada y barata en distintas regiones. Un ejemplo familiar para mí es la industria de la maquila. Mientras que una obrera puede ganar alrededor de 3,5 dólares en Estados Unidos, en América Central se paga 0,75 centavos de dólar por la misma función. Un proceso similar se puede reconocer en el caso del capital financiero, el cual trata de trasladar inversiones de un país a otro, procurando mejores tasas de interés y convirtiendo a la economía capitalista en una actividad marcadamente especulativa.

La globalización se distinguiría de los procesos descritos anteriormente, pues además de la producción y el capital financiero, involucra la cultura. Las industrias culturales se globalizan y en distintos lugares del planeta se empiezan a extender ciertos formatos y programas. Hay una compresión del espacio/tiempo, que también se conoce como deterritorialización, pues los bienes culturales circulan no sólo en donde fueron producidos sino que tienden a superar barreras geográficas y lingüísticas. Los Simpson, por ejemplo, se traduce a más de 30 idiomas. Conviene eso sí subrayar que la glohalización de la cultura no es un proceso monolítico. Basta con recordar que apenas cerca de un 10 por ciento de la población cuenta con acceso a internet. Como ha sido a lo largo de la modernidad, internet se ha expandido a ambos lados del Atlántico. Saskia Sassen, una de las analistas más agudas de los procesos globalizantes, anota que en Manhattan existe el mayor cableado de fibra óptica en el mundo, sin embargo, dos millas al norte, en el Harlem, un área habitada 
por comunidades negras y latinas, sólo había, en 1995, un edificio que disponía de tal tendido. Es decir, la globalización ha acercado como nunca antes la opulencia y la pobreza.

En términos más generales, se podría afirmar que hay una relación muy sugerente entre procesos globalizantes, modos de comunicación y representación de la alteridad. Enseguida trataré de ilustrar esta relación. Saskia Sassen ha sugerido que la globalización, más que un fenómeno generalizado se muestra más fuertemente en ciudades como Nueva York, Londres o Tokio y ha estado acompañada por procesos de desindustrialización, en donde sobre todo la industria metalúrgica ha sido reemplazada por una economía de servicios y por regímenes de contratación flexibles, llamados también postfordismo, en los cuales las personas no son contratadas por las compañías directamente sino por agencias de empleo. Acá en Costa Rica, estos regímenes llamados "flexibles" ya operan en el sector público, a través de la contratación de servicios profesionales o a través de la privatización de los servicios de mantenimiento y limpieza.

Esta transición de la industria a los servicios, bajo nuevos sistemas de contratación, está teniendo implicaciones importantes en la estructura social. En su análisis, Sassen advierte dos cambios importantes. Uno sería que un sector de las clases medias se convierte en parte de las capas gerenciales, sobre todo del capital financiero, quienes reciben generosos salarios de 15 mil dólares y más por mes. Otro cambio estaría caracterizado por el efecto contrario, es decir, un sector importante de lo que antes serían las capas medias estaría perdiendo terreno, toda vez que el mayor número de empleos que se generan en este nuevo escenario económico consiste en labores de mantenimiento y limpieza, comidas rápidas, cuido de niños, entre otros. Así, mientras 
que durante el día los grandes centros financieros están poblados de elegantes hombres y mujeres mayormente caucásicas; por la noche y la madrugada, miles de inmigrantes latinos en Nueva York, por ejemplo, se ocupan de dejar relucientes las oficinas del capital financiero.

Estas transformaciones están teniendo expresión en los modos de comunicación. Estas tendencias nos pueden ilustrar de manera muy provisional y tentativa. Una de las series más exitosas de la televisión estadounidense, vista en ambos lados del Atlántico, es Ally McBell, compuesta por un grupo de abogados y abogadas jóvenes, quienes llevan casos controversiales, laboran en una zona agradable de Nueva York y no parecen tener dificultades económicas. Ally y sus colegas habitan este mundo de las nuevas capas gerenciales que son algo así como los triunfadores de la globalización. Al otro lado del espectro, encontraríamos lo que algunos llaman la "televisión tabloide", es decir, el traslado de ciertos patrones, características de la prensa sensacionalista y amarillista a la televisión, especialmente en la forma de shows y noticieros sobre lo "insólito". "Ocurrió asî", es un ejemplo familiar para nosotros de esta segunda tendencia. No es casual que la mayoría de los invitados a los shows sean latinos, quienes debaten sus vidas en público. Como estos ejemplos, podríamos encontrar otros, pero quizá basten para ilustrar esta relación entre organización social y modos de comunicación. Lamentablemente, acá en Costa Rica ya tenemos un noticiero televisivo que ejemplifica esta tabloidización de la televisión.

Mientras tanto, una tercera dimensión es la representación de la alteridad, es decir del otro, en estos tiempos globalizantes. Quizá sea importante recordar que la globalización de la cultura y la economía ha estado acompañada de 
un cambio político crucial, de una ideología basada en la oposición "comunismo-democracia", llamada "Guerra Fría", a un nuevo escenario en donde las diferencias étnicas y nacionales se han politizado. John Gabriel y otros autores llaman a este nuevo escenario una política racializada, que se ilustra con los modos de representar a la comunidad latina en Estados Unidos o los ciudadanos de la ex Yugoslavia en los países que forman parte de la Unión Europea. Desde luego, el ejemplo más cercano a nosotros es el de los nicaragüenses en Costa Rica. En diversos contextos, se percibe a los inmigrantes como una amenaza que debilita la nación. Antes la amenaza se asociaba con los sandinistas, ahora "nica", sin importar afiliaciones políticas, se ha vuelto ofensiva. Incluso, entre jóvenes, se emplea la expresión "no sea nica", a la cual se recurre cuando se quiere ridiculizar a alguna persona. Bien se podría decir que los "inmigrantes" son los comunistas del siglo XXI.

\section{Algunos retos de la comunicación universitaria}

Como se puede observar, la globalización incluye tendencias culturales y económicas en diferentes escalas y espacios temporales e integra nuevas interrogantes al análisis de las sociedades contemporáneas. En esta última parte de mi contribución, quisiera elaborar algunas ideas que podrían contribuir al diseño de políticas de información y comunicación en las oficinas de prensa y divulgación de las universidades públicas y otras instituciones vinculadas con el sector de ciencia y tecnología. Quizá el punto de partida sería el considerar que las universidades están llamadas a ser instituciones propiciadoras de una actitud reflexiva en esta modernidad tardía. Ello implica asumir no sólo una actitud instrumental, sino sobre todo una actitud dialógica y constructiva en torno a los principales desafíos nacionales e internacionales. 
Esta actitud reflexiva demanda algunas disposiciones de partida. Una primera cualidad sería la capacidad prospectiva, que facilite la previsión de escenarios futuros en donde las universidades públicas estarían llamadas a actuar. Una segunda sería una actitud propositiva, es decir, capaz de generar agendas de discusión que incorporen la crítica y la autocrítica, pero también estrategias de intervención en problemas centrales de la sociedad costarricense y de las universidades mismas. En tercer lugar, una tercera actitud indispensable es asumir una posición proactiva, que permita innovar y no sólo reaccionar frente a problemas existentes. Estas disposiciones prospectivas, propositivas y proactivas son requeridas tanto en las relaciones de las universidades con el resto de la comunidad nacional como también en el ámbito interno, en donde hay inercias que conviene discutir.

En el ámbito externo, quisiera subrayar la importancia de generar pensamiento crítico en torno a la globalización. A lo mejor una pregunta central es interrogarse sobre las posibilidades de una globalización no neoliberal. Es evidente que los procesos globalizantes han incrementado la exclusión social. De hecho parece que "exclusión social" es la forma contemporánea de referirse a injusticias sociales. Sin embargo, no parece haber discursos propositivos que transformen las protestas anti-neoliberales en propuestas. Acá yo vería uno de los principales vacíos en las universidades públicas. Es decir, mientras hay una creciente red de intelectuales y tecnócratas afines a la globalización neoliberal, las universidades presentan un enorme vacío propositivo y proactivo. La década de 1980 fue llamada por la CEPAL como la "década pérdida", pero no parece haber alternativas de desarrollo menos excluyentes. De hecho para miles de jóvenes costarricenses, la semana universitaria es el único modo de vinculación con la Universidad de Costa Rica. 
A lo mejor esta carencia propositiva tenga que ver con la feudalización de las universidades. Son evidentes las dificultades para discutir con colegas de campos diferentes a los de uno, lo mismo con colegas que laboran en diferentes instituciones. Es decir, mientras las tendencias globalizantes se expanden, las posibilidades de redes intelectuales que formulen políticas más incluyentes, se vuelve más difícil. Desde luego, hay esfuerzos encomiables, pero sin duda el deterioro de la calidad de vida en Centroamérica y en América Latina demanda esfuerzos mayores.

Acá señalaría la importancia de diseñar estrategias de comunicación e información conjuntas entre las universidades públicas, que optimicen el uso de los recursos y que tengan un mayor impacto. A lo mejor este encuentro podría facilitar el inicio de las discusiones. En particular, sugeriría tres áreas de intervención. Una se refiere a las posibilidades de relación con el sector productivo sobre todo en términos de acompañar la innovación tecnológica, una segunda instancia de intervención remite a las posibilidades de participar en la formulación de políticas públicas y en general en la constitución de la agenda pública, una tercer área involucra las relaciones con la sociedad civil. A continuación quisiera referirme brevemente a cada una de ellas.

Las relaciones con el sector productivo podrían propiciar la innovación tecnológica. Basta pensar en lo poco que aprovechamos acá la energía solar. Tenemos aproximadamente 12 horas de luz natural y calor. Sin embargo, en muchos edificios de la Universidad de Costa Rica no se puede trabajar si no se encienden las luces, incluso si es mediodía y afuera hay pleno sol. Esta carencia es comprensible porque la Revolución Industrial ocurrió en regiones en donde el sol es una ilusión y los días nublados la regla. Pero acá requerimos 
de la innovación tecnológica y la cooperación empresarial para aprovechar nuestros recursos. Si sólo pudiéramos iluminar los edificios de las universidades con energía solar, ya habríamos empezado a dar respuestas inteligentes a estos nuevos tiempos. Este tipo de iniciativas, además, confirma que el compromiso de las universidades públicas con el sector empresarial no radica, en lo fundamental, en ofrecer cursos de inglés y Windows. Es lo más fácil, pero tal vez no lo decisivo. Se requiere generar conocimiento y no sólo difundir el ya existente.

Un segundo campo que a mi juicio es particularmente importante, se interroga sobre cómo las universidades podrían incidir en la agenda o esfera pública y en la formulación de políticas públicas. Un ejemplo aleccionador que me parece que nos podría ayudar esta mañana es el de "violencia doméstica". Hasta hace algunos años, los medios y las instituciones públicas no registraban, en términos de discursos públicos o políticas públicas, la existencia de violencia doméstica. Es decir, no constituía tema de conversación ni un campo de legislación. Es solo después de varios años de investigación y debate en el campo de los estudios de género que el concepto de "violencia doméstica" dejó de ser tema exclusivo de especialistas y ha trascendido a la esfera pública y ha sido objeto de legislación. Este es un ejemplo que nos muestra que la investigación, desarrollada en torno a temas decisivos, puede aportar mucho a volver menos injusta la vida, que es después, de todo, el motivo de las universidades y la comunicación.

Este ejemplo nos podría conducir a otro. En los últimos meses, los reportes de los medios de comunicación nos han advertido que, en promedio, dos personas pierden la vida en accidentes de tránsito. Es algo así como tener un 
conflicto armado, aunque sin la espectacularidad de la guerra, aunque la pérdida de vidas humanas genere el mismo dolor. Las noticias subrayan el exceso de velocidad, el consumo de licor, el número creciente de automóviles y el deterioro de las vías de comunicación como posibles explicaciones. Posiblemente, estos factores sean importantes, pero yo sugeriría que muchos de estos factores son, por así decirlo síntomas y no propiamente causas. Más bien apuntaría que si algo se expresa en el adelantar es falso, tomar excesivamente son formas históricas de masculinidad caracterizadas por la intolerancia y la necesidad de externalizar poder a costa de otros ciudadanos. Es decir, la discusión pública de cómo se han constituido las formas hegemónicas o predominantes de masculinidad es una condición imprescindible para superar esta fuente de dolor y muerte en que vivimos. Si pudiéramos convertir el tema de las masculinidades en asunto de discusión pública, como ha sucedido con violencia doméstica, estaríamos cumpliendo con los objetivos de las universidades públicas.

El tercer campo de intervención se sitúa en relación con la sociedad civil. Puede ser evidente, pero no estaría mal insistir, que el mercado no es la sociedad y quisiera señalar que una debilidad clara en las universidades públicas es lo marginal que resulta la acción social en el conjunto de las actividades universitarias. La acción social no sólo implica contribuir al mejoramiento de la calidad de vida de determinados sectores sociales, sino un modo de reconocer carencias y necesidades en una sociedad. Es decir, la investigación y la docencia tienen mucho que ganar con la acción social. Este reconocimiento es clave, además, para establecer políticas de investigación. A veces siento, que al menos en ciencias sociales, mi campo, hay una marcada tendencia hacia el llamado "empirismo de escritorio", el cual reemplaza 
el análisis de primera mano de procesos, prácticas y actores sociales.

En el ámbito interno de las universidades, quisiera subrayar dos aspectos que me parece no han recibido la suficiente atención. Uno es que a pesar de que se afirma que vivimos en sociedades de la información y el conocimiento, diría que la preparación de las generaciones de relevo en las universidades públicas no ha sido prioridad. $\mathrm{Al}$ menos es mi impresión de la Universidad de Costa Rica. Una política de recursos humanos proactiva, es decir, capaz de anticiparse a un déficit de personal altamente calificado debería ser un tema que contenga más relevancia. Ello nos obliga a mejorar los sistemas de información y priorizar la formación de recursos humanos. Los expertos dicen que el recurso humano es lo más valioso en las organizaciones, sin embargo, yo no veo cómo dicha conclusión se traduce en políticas institucionales. Es un secreto a voces que en la Universidad de Costa Rica se pierden becas. Es decir, no todos los problemas se reducen a falta de recursos, a veces el problema es que no sabemos cómo emplear los que ya tenemos.

Un segundo aspecto que convendría discutir es cómo generar procesos de discusión interna más inclusivos. Uno de los aspectos paradójicos, al menos en la Universidad de Costa Rica, es que internet no se emplea para propiciar el debate interno sobre los desafíos claves de la institución. Internet ofrece un enorme potencial para crear comunidades académicas activas y también para generar procesos de autocrítica sobre la marcha de la institución. Sin embargo, las facilidades que propician estos cambios tecnológicos no se ven acompañadas con innovaciones en la toma de decisiones. En otras palabras, mi sensación es que las universidades públicas, en virtud de su crecimiento y diversificación, se 
han vuelto organizaciones muy complejas, en donde las posibilidades de comunicación y debate se han jerarquizado de manera considerable. Está muy bien que hayan asambleas colegiadas o congresos universitarios, pero la discusión, debate y ejecución de políticas podrían ser una práctica cotidiana si empleáramos más dialógicamente las ya no tan nuevas tecnologías. El problema, pues, es que el desarrollo tecnológico ha caminado más rápido que la transformación de los modelos de gestión universitaria. Acá hay un tema central para el debate y sobre todo para la autocrítica.

Quisiera terminar subrayando que la acción concertada de las universidades no sólo debería atender los desafíos externos sino que las iniciativas deberían iniciar por casa. Podríamos, por ejemplo, contar con sistemas de información y comunicación electrónicas. Las organizaciones políticas nacionales, por ejemplo, emplean el servidor cariari de la UCR para distribuir sus mensajes, pero las universidades públicas no están enlazadas. Es también llamativo cómo la posibilidad de enlazar las sedes y recintos de las universidades públicas no sea un tema estratégico, pese a que ello podría mejorar, por ejemplo, la calidad de la enseñanza. En fin, si sólo pudiéramos sistematizar y ejecutar algunas de las tantas iniciativas para mejorar las universidades públicas que soñamos entre tazas de café de todos los días, habríamos dado un enorme paso. 